\title{
Nutrition education at the university level
}

\section{By K. J. Carpenter, Department of Applied Biology, University of Cambridge, Pembroke Street, Cambridge CB2 $3 D X$}

University education in any scientific subject seems full of paradoxes. As Lord Ashby has said, universities have two duties-to pass on the accumulated knowledge of previous generations and at the same time to encourage and teach new generations to think for themselves. Lastly, or perhaps firstly, a university must also encourage and provide time for a student to 'find' himself in the adult world and to work out a set of values by which he can judge himself and the consequences of what he does. To quote an American writer: 'Intellectual barbarism seems to be fairly evenly distributed in the main scholarly disciplines dealing with the phenomenon 'man' ... [by which I mean] an ignorance of history and philosophy, narrow expertise without wider horizons, a preoccupation with technical skills, and total insensitivity to the use of language' (Berger, 1963).

It is also a strange fact that university teaching officers are typically taken on as a result of their having done a successful piece of research, but having no training or experience in teaching. They are then put to teach still without any training in how to do it. However, the system seems to work, and in autobiographies of successful people one repeatedly reads how they were stimulated by teachers who were hopeless lecturers, but somehow conveyed an intimate and compelling impression of unresolved problems and the nature of scientific work, far more than they were by the rest of us who try to teach 'correctly' and systematically.

As for the subject of 'Nutrition', there is controversy about its nature and scope. In a thoughtful paper, Harper ( 1969 ) says: '.. . there is a science of nutrition and a practice of nutrition and the same word is used for both.... It will contribute to clearer thinking about nutrition as a field of endeavour if we learn to recognize when we are participating in one and when in the other'. I agree. And the special feature of nutrition education at the university level is that it must provide both for people who will be going on to engage in the practice of nutrition and teaching at lower levels, i.e. giving the best advice they can in the light of what seem to be the established 'facts' of our subject, and for people who will be going on to question whether these are 'facts' at all, and trying to find and test entirely different ways of looking at the subject.

The distinction does help to clarify what kinds of education are required by different student groups. For example, in the education of the medical, dental or veterinary student with no special interest in our subject, we need to use the necessarily small portions of their courses that are allocated to nutrition so that they can apply what they have learnt directly and in a practical way to their 
patients' welfare. It would seem, for example, of no use to such students to know the names of the enzyme systems with which ribofiavin is concerned if this information has no obvious connexion with the usual signs of riboflavin deficiency or the circumstances in which it might be encountered. Similar considerations should apply in the nutrition part of a training in food technology, agriculture, etc. There is a kind of snobbery about nutritional biochemistry that makes it seem more high-class than nutrition in terms of actual foods, but it is the latter type of knowledge that the practitioner in all these professions needs, and so often lacks.

Cowell (1953) posed the question how far nutrition should be taught to medical students as a separate subject, and how far as something coming up directly in different clinical connexions. The latter will serve to reinforce the earlier, basic and systematic nutritional teaching but can hardly replace it. Also the clinical teaching staff may neither have an up-to-date knowledge of nutrition themselves nor a colleague to turn to for advice.

Now for students whose special interest is nutrition and who want to become 'nutritionists'. The largest Department of Nutrition in the UK, and the first to provide an Honours first degree in the subject, is at Queen Elizabeth College, I.ondon (Copping, 1953). Graduates from this course have branched off in many directions but Yudkin (1953, 1960) has made it clear that one of the prime purposes for which it was first designed in 1952 was to train people who could teach nutrition at domestic science colleges, i.e. to those who would in turn be teaching cooking and housecrafts at ordinary schools, and including a 'nutrition' element in this teaching. In this way it was hoped to breal a circle in which generations of domestic science teachers were training their own successors in increasingly out-of-date nutritional knowledge.

An important and novel feature of the course bas been its double bes: the conventional biological sciences and also the social aciences. This is because what people eat is determined by social and economic factors and one can only hope to persuade them to change their habits for the better if one underatands why they behave as they do. Like many innovations it took great courage at the time, when other people failed to understand why it was being done, and now that it coems so obviously correct, the originality of those responsible is forgotien.

The London BSc (Nutrition) degree is also uned ss a preliminary to a professional 'dictetics' qualification, so strengtheniog this profession also with potential leaders having a stronger scientific background than most for the practice of nutrition. In Latin America the combined term 'nutritionist-dietitian' is now being used to describe someone with training to a professional standard in public health (or community) nutrition and also in hospital dietetics (Bosley, 1975) and perhaps we should follow their lead. There is confusion amongat employers as to how much responsibility they can give to people who do not possess a ipecific professional qualification.

If it is accepted that some knowledge of the social sciences is a vital ingredient in the successful practice of nutrition, should they also be considered part of the science itself This is more controversial. The conventional view has been that: 
'Nutrition is a branch of biology concerned with the study of food and its relation to health, describing the relationship in physical and chemical detail-not an independent science but drawing on the basic sciences of chemistry, physics and biology' (Harper, 1969). Later in this symposium, Oddy (1976) will be making the case for psychology and other social sciences being at the centre of the branches of knowledge concerned with what people eat, and whether or not they suffer from malnutrition, and that they must therefore form a central part of the studies which go together to make up the integrated 'science of nutrition'.

The recent report by the ARC/MRC Committee (1974), Food and Nutrition Research, has been attacked for its relative neglect of the need for research into the social aspects of malnutrition. And it has been argued that this reflects the unnecessarily narrow views of the traditionally trained biochemists and medical men who had been selected to constitute the committee. The controversy is relevant to this Symposium. In planning the training for a job, we need to know its nature. As with most arguments, one can accept the premise and still draw a different conclusion. Thus, Barnes ( 1975 ) from Cornell University has urged 'the critical need for the expansion of interdisciplinary research relating to nutrition, but primarily through collaborators with major training and expertise in specific fields rather than a single, jack-of-all-trades nutritionist attempting to be a sociologist, a psychologist or perhaps an economist as well'.

Perhaps the controversy so far as nutrition education is concerned is really a matter of degree. Just as science students traditionally gained some acquaintance with a foreign language in the course of their training so that they could establish a reasonable level of communication with workers from that country, the nutrition student might now be expected to gain enough knowledge of the social sciences to communicate intelligently in later life with specialists from those disciplines, to learn the kind of thing that they could be expected to contribute to a collaborative investigation and to develop some sympathy with their approach to a problem. A book such as Communication of Innovations (Rogers \& Shoemaker, 1971) is an excellent start to convert the nutritionist in this direction.

This, of course, leads us on to the question of what is likely to be the most helpful type of training for people intending to specialize in the science of nutrition. I do not think that any one pattern is essential. If someone has the keenness and determination (and his or her education does not positively snuff it out), and the basic ability and an education in some branch of science, they will overcome the obstacles and teach themselves to be a useful nutritionist of some kind. We can see that from the backgrounds of leading nutritionists, past and present.

It can also be an advantage to have some people approaching nutrition from different disciplines. There is always a danger of a 'School of Nutrition' getting set into a particular, and thus limiting, view point which its students adopt unconsciously. To quote Harper (1969) again: 'there is no such thing as a nutritionist, there are nutritionists. ... We are chemists, biochemists, pathologists ... dietitians ... sociologists ... toxicologists and many others ... we are in different places going in different directions.' 
But if some very exceptional men are able to surmount obstacles in their path without aid it still takes time, and the rest of us need all the help that we can get to do it at all. We must, first, be trained to be professional scientists, i.e., the opposite of amateur cranks with whom it is impossible to argue because they are unable (or unwilling) to assess evidence objectively to test their beliefs. I believe that courses in biometry and the design and analysis of experiments are essential, and are particularly difficult subjects for people to 'get up' later on without the opportunity for practice and discussion that a university course can provide.

The same holds true for the other sciences on which one is going to base one's work. In the laboratory, for example, the real understanding of nutritional assays involving enzymes requires a biochemical training in the properties and functions of enzymes. Without it one can 'follow the instructions on the packet' but when things go wrong one can lose a lot of time or, worse still, fail to spot that there is trouble and accept erroneous results. In other words, whatever one does one should be able to do it with fair understanding.

A common criticism of undergraduate training is that it consists of getting students to know things, whilst an actual scientific career consists of doing and the assessing of complex, incomplete data; for which graduates may be quite unprepared (Ashby, 1971; Ravetz, 1971; Everson, 1975). Fuller (1975), arguing the case for university courses for experimenters, takes the analogy of playing golf: the properties of the ball and of the club are relevant, but one only actually learns by playing, i.e. doing. This is the argument for students' individual projects. It is difficult to strike a balance and 'projects' are time-consuming for both staff and students, and relatively expensive, but I feel convinced that we cannot afford not to have them.

Lastly, the student must be shown evidence for believing that our present knowledge is only partial, and based on assumptions of which we are at present unaware; also for understanding that the present generation is not cleverer or wiser than its predecessors, only that we are lucky enough to have the results of their work to hand. Examples of writing that may catch a student's interest in the history of our subject are the book by Etheridge (1972) on the social history of pellagra in the southern USA and that by Mellanby (1950) on the old controversies over the cause and cure of rickets, and also papers such as that by O'Hara-May (1971) on the history of 'measuring man's needs'. Professor Ostwald is quoted (Camac, 1959) as saying 'I learned that every scientific discovery is the result of a natural process of development leading through more or less numerous errors and misconceptions and that the inclination to view a question from a historical standpoint is of the same importance in the education of an investigator as is the inclination and ability to do careful and conscientious experimental work'.

It is a fortunate fact that some people develop a special interest in nutrition, and wish to specialize in it, after doing a first degree in a basic science, e.g. physiology or biochemistry, or after a full professional training in medicine or as a veterinarian. In the past the practice at some otherwise reputable universities was for such a person to do a piece of research under supervision, say on the changes in 
a particular tissue in rats deficient in a particular nutrient, and then to receive a PhD degree in nutrition and thus, by inference, the title of 'nutritionist'. This is ridiculous. If such graduates do eventually become nutritionists it is because they are more-or-less self-educated.

I speak from personal experience and, because of it, I campaigned for Cambridge University to set up a $\mathrm{r}$-year postgraduate course to provide systematic education during the first year of work for a $\mathrm{PhD}$ in nutrition (Kodicek \& Carpenter, r 969). We have designed our course principally for someone aiming to be a laboratory worker in the science, choosing this facet of nutrition because it seemed to be the thing that the particular combination of departments and research institutes in and around Cambridge could do best, and one where different people interested primarily in either animal or human nutrition could work together, both as students and as teachers.

Apart from lectures covering basic nutritional teaching (with no special novelty) and biometry, the student group carry out five class projects in different laboratories, learning to use techniques such as calorimetry, gas-liquid chromatography (GLC), isotope tracer work, microbiological assays, haematology and so on. Equally important, they analyse and discuss the interpretation of the results obtained.

One of these projects, for example, is an investigation of the effect of feeding different fats to rats on the fatty acid composition of their tissues. This allows discussion of an economical design of experiment, the preparation of balanced diets, the handling of small animals, measurements of food consumption, preparation of carcasses for analysis and GLC analysis of methyl esters of fatty acids, all in 3 weeks. It also provides experience of handling and interpreting a considerable quantity of data. Using laboratory animals does not contravene the Vivisection Act as the diets are all calculated to be fully balanced.

The remaining half of each student's time in the academic year is spent on an individual research project which has to be written up and is examined, together with three written papers. Completion of the course can be an end in itself or just the Ist year of work towards the PhD degree.

With this type of teaching, and the mounting of projects in various institutes, the practicable upper limit to our class size is ten. But even if, in practice, only five of these come from the UK itself, we are concerned with their career prospects. Perhaps it is an inevitable problem. Although we in the Nutrition Society may agree about the need for more nutritional research we are not ourselves in a position to put up the necessary money.

Some other graduate courses are designed particularly for people who expect to be engaged in field work in the developing countries, for example that at the London School of Hygiene and Tropical Medicine. In such courses the majority of places may be filled by graduate students from the developing countries, who already have a post to which they will return. These can therefore be viable with only a small number of UK students. We on the teaching staff of British universities do have to take a responsible attitude about encouraging students to 
enter our courses. Certainly it would be wrong to hold out false hopes of career prospects in order to bolster up student numbers.

At Cambridge we have a number of different undergraduate courses in which 'nutrition' forms a part, and I would like to mention one in particular. This is called 'Biological Resources' and can form half of the 3 rd (i.e. final) year's work for undergraduates in science, medicine or veterinary studies. Most students in their 3 rd year study one basic science in detail but this is not the most appropriate use of their time for all students and the Biological Resources course provides a broader background to biological subjects, with sections on population, food supply, principles of food production, nutrition, world energy and mineral resources, etc. We thought of it originally as suitable for scientists going into teaching or administration, but it has proved attractive also to a proportion of medical and veterinary students who are interested in relating their special subjects to the context of the over-all physical limitations to life on the Earth, and how it is and will be affected by recent changes.

This brings me back to my first point. Science has proved such a powerful tool that we must try to educate ourselves, along with our students, not to swing it about like a toy, enjoying the feel of its power. While we can ruthlessly and unreservedly try to find the truth about things, this is not the same as applying scientific and technical novelties to the ultimate limit if it means distorting and standardizing humanity in the process. The 'Concorde' project is one example of the abuse of science and technology to many people. To me a modern battery house for laying hens, three to a small cage and in very dim lighting, is another. To produce a stable, dry powder diet that will support a high level of productivity without the birds needing access to fresh grass or sunlight is a technically successful application of the science of nutrition. But, by exploiting another species in this way, and using to such a purpose the classical research which unravelled the complexity of vitamins $A$ and $D$ and succeeded in their synthesis (i.e. the work of those people who were the life-giving heroes of our own student days) are we not taking another step towards degrading and brutalizing Western man, and breaking yet another strand in his link with Nature? I believe that we are, and that we must do our best to educate the new generation to see the dangers of uncontrolled applications of science, not only the physical and biological dangers but also those to our spirit and raison d'etre. Only in that context can nutrition education be truly a blessing to mankind, and something to which we can put our energies unreservedly.

To paraphrase Francis Bacon: 'the true ends of knowledge are not for profit or fame or power, but for the benefit and use of life ... govern it with charity'.

\section{REFERENCES}

ARC/MRC Committee (1974). Food and Nutrition Research. Report of the ARC/MRC Committee. London: H.M. Stationery Office.

Ashby, E. (1971). Proc. R. Soc. B 178, 29.

Barnes, R. H. (1975). Nutr. Notes, June, p. 3.

Berger, P. L. (1963). Invitation to Sociology, p. 12. New York: Doubleday. 
Bosley, B. (1975). Wld Rev. Nutr. Diet. $20,49$.

Camac, C. N. B. (1959). Classics of Medicine \& Surgery, vol. 6. New York: Dover Publications. Copping, A. M. (1953). Proc. Nutr. Soc. 12, 177.

Cowell, J. S. (1953). Proc. Nutr. Soc. 12, 173.

Etheridge, E. W. (1972). The Butterfy Caste. Westport, Connecticut: Greenwood.

Everson, R. G. (1975). Biologist 22, 123.

Fuller, O. M. (1975). Chemy Ind. no. 21, p. 546.

Harper, A. E. (1969). Am. F. clin. Nutr. 22,87.

Kodicek, E. \& Carpenter, K. J. (1969). Biblthca 'Nutr. Dieta' no. 13, p. 173.

Oddy, D. J. (1976). Proc. Nutr. Soc. 35, 139.

O'Hare-May, J. (1971). F. Hist. Biol. 4, 249.

Mellanby, E. (1950). A Story of Nutritional Research. Baltimore, Maryland: Williams \& Wilkins.

Ravetz, J. R. (1971). Scientific Knowledge and its Social Problems, ch. 3. London: Oxford University Press.

Rogers, E. M. \& Shoemaker, F. F. (1971). Communication of Innovations. London: CollierMacMillan.

Yudkin, J. (1953). Proc. Nutr. Soc. 12, 198.

Yudkin, J. (1960). Nutrition, Lond. 14, 151. 